\section{Investigación biomédica en Chile: Algunos comentarios. Respuesta}

\section{Reflections on current biomedical research, in Chile. Reply}

\section{Respuesta al Dr. F. Cabello:}

Agradecemos los comentarios de un prestigioso investigador chileno en microbiología, desde su sede universitaria en Norteamérica. El Dr. Cabello está sorprendido por la similitud de los recursos proporcionados por fondos estatales concursables para investigación biomédica y clínica en Chile, y los recursos que empresas farmacéuticas extranjeras destinan para ensayos clínicos ${ }^{1}$. Además, extiende su sorpresa a la ausencia de un registro con acceso público y obligatorio para los ensayos clínicos que se realizan en nuestro país.

Aunque ambas situaciones fueron destacadas en nuestro documento, su carta nos permite ahondar en ellas. Una mirada global a los proyectos de investigación biomédica y clínica con financiamiento estatal concursable hace notar que sus objetivos apuntan principalmente a la generación de conocimiento original, mientras podemos presumir que los proyectos financiados particularmente por entidades de la industria farmacéutica con sede principal en países de Norteamérica y Europa, persigue extender experiencias multinacionales, con nuevos medicamentos, vacunas, tecnología de creación reciente, etc. Nuestra impresión se basa en que son mayoritariamente proyectos multinacionales, en que los investigadores chilenos participan siguiendo protocolos generados en las sedes principales de las instituciones de investigación y desarrollo (I\&D). Surgen preguntas que convendría aclarar: ¿Cómo se compara esta situación con respecto a los Estados Unidos de Norteamérica? ¿Con qué proporción de recursos estatales se financian los ensayos clínicos en ese país?

La preocupación por disponer en Chile de un Registro Nacional de Ensayos Clínicos, con las características establecidas por organismos con sólido prestigio internacional, es desde el año 2006 un motivo de análisis reiterado en diversas instancias, incluyendo revistas médicas chilenas y dependencias del Ministerio de Salud, como lo indica una editorial en la Revista Médica de Chile, en 2009².

Nuestro estudio reciente detectó que en el período 2008-2009 sólo siete publicaciones indexa- das en PubMed fueron ensayos clínicos en que se reconocen autores e instituciones nacionales. $\mathrm{Si}$ este dato persistiera en el tiempo, resultará difícil justificar el costo que implicaría crear un Registro Nacional que cumpla los propósitos y emplee la metodología de la normativa internacional.

Los ensayos clínicos multinacionales financiados por instituciones de I\&D con sedes en el extranjero, son publicados en revistas extranjeras y a ellas corresponde exigir el correspondiente registro, en el país sede del estudio, lo que generalmente le confiere validez internacional. Para los escasos ensayos clínicos estrictamente nacionales queda abierta la alternativa de registrarlos en otros países latinoamericanos, lo que merece ser considerado ${ }^{3,4}$.

Es pertinente recordar que todo ensayo clínico realizado en Chile, particularmente en hospitales públicos o universitarios, cualquiera sea la procedencia de su financiamiento, requiere ser aprobado por el Comité local de Ética de la Investigación y, si es un ensayo de fármacos, vacunas, etc., debe ser autorizado por el Instituto de Salud Pública. Lamentablemente, el registro en este Instituto no tiene acceso público en Internet, no exhibe un control periódico de los resultados parciales ni los finales, lo cual lo deja fuera del espíritu que tienen los Registros de Ensayos Clínicos.

Esperamos, tal como el Dr. Cabello, que nuestro catastro estimule la adopción de una política oficial y estatal, que controle todos los ensayos clínicos en nuestro país y haga transparente y pública la información sobre su marcha y resultados. Debemos recordar que, si bien los Registros de Ensayos Clínicos exigen identificar todas las entidades que patrocinan o financian cada ensayo, no piden declarar el monto de recursos aportados ni si incluyen el pago de honorarios a investigadores: ello es controlado en otra instancia, siguiendo disposiciones legislativas propias de cada país. Recientemente, la legislación estadounidense adoptó mayor estrictez a este proceso, al aprobar un Decreto de Transparencia de los Ensayos y Estudios Experimentales ("Trial and Experimental Studies Transparency (TEST) Act") que, entre otras novedades, incorporó la exigencia de estar registrados en ClinicalTrials.com (base de datos con acceso público) incluso para los ensayos de fármacos o instrumentos que fueron hechos fuera de los Estados Unidos de Norteamérica pero pretenden ser aprobados por la Food and Drug Administration (FDA) ${ }^{5}$. 
Las revistas médicas juegan un rol crucial en este proceso. Desde 2005 un número creciente de revistas exige que todo ensayo clínico certifique haber sido incorporado oportunamente en un Registro oficial, desde antes de incorporar la primera persona sujeta a dicho ensayo. De lo contrario, no se acepta revisar ese manuscrito.

La nueva Ley sobre Derechos y Deberes de los Pacientes da pie para seguir insistiendo. Concordamos con nuestro corresponsal en que la Academia Chilena de Medicina constituye una excelente instancia para dirigir esta cruzada que pretende "proteger a quienes están dispuestos a someterse al riesgo de ensayar nuevos enfoques de diagnóstico y terapéutica... sin los cuales no podría progresar la medicina"s.

Gloria Valdés S. ${ }^{1}$, Humberto Reyes B. ${ }^{2}$ ${ }^{1}$ Facultad de Medicina, Pontificia Universidad Católica de Chile. ${ }^{2}$ Facultad de Medicina, Universidad de Chile.

\section{Referencias}

1. Valdés G, Armas Merino R, Reyes H. Principales características de la investigación biomédica actual, en Chile. Rev Med Chile 2012; 140: 484-92.

2. Reyes H, Andresen M, Palma J. La Revista Médica de Chile en el año 2009. Rev Med Chile 2009; 137: 1089.94.

3. Reveiz L, Delgado MB, Urrutia G, Ortiz Z, García Dieguez M, Martí-Carvajal A, et al. Latin American Ongoing Clinical Trial Register (LATINREC). Rev Panam Salud Publica 2006; 19 (6): 417-22.

4. Registro Brasileiro de Ensaios Clínicos. Accesible en www.ensaiosclinicos.gov.br/\%29.

5. Drazen, JM. Transparency for Clinical Trials - The TEST Act (Editorial). N Engl J Med 2012; 367 (9): 863-4. 